\title{
Granuloma piogênico em lábio inferior - relato de caso
}

\author{
Pyogenic granuloma in lower lip - case report \\ Granuloma piógeno en labio inferior - reporte de caso
}

\section{Resumo}

O granuloma piogênico (GP) é uma lesão benigna, não neoplásica na cavidade oral, sendo considerado um Processo Proliferativo Não Neoplásico (PPNN). É uma das entidades mais frequentemente associadas à expansão dos tecidos moles da cavidade bucal, tendo preferência por indivíduos do gênero feminino, na faixa etária entre a $2^{\mathrm{a}}$. e a $4^{\mathrm{a}}$. década de vida. O tratamento de eleição é sua excisão cirúrgica com pequena margem de segurança, devendo os agentes irritantes serem concomitantemente removidos para a cura da lesão. Este trabalho teve como objetivo relatar um caso de granuloma piogênico lábio inferior associado a trauma casual num paciente do gênero masculino com 20 anos de idade. Os autores concluem enaltecendo a importância do conhecimento da patologia bucal pelo Cirurgião-Dentista no sentido de realizar um correto diagnóstico diferencial de outras lesões para realização do tratamento adequado.

Palavras-chave: Granuloma piogênico; Patologia bucal; Cirurgia bucal.

\begin{abstract}
Pyogenic granuloma is a very common non-neoplasic benign lesion in the oral cavity, being considered as a nonneoplasic proliferative process (NNPP). It is one of the entities most frequently associated with soft tissues expansions of the oral cavity, having preference for females, in the age group between the 2 nd. and the 4 th. decade of life. The treatment is by surgical excision with a small margin of safety, and irritants should be concomitantly removed for healing of the lesion. This study aimed to report a case of pyogenic granuloma in lower lip with casual trauma in a 20 - year - old male patient. The authors concluded by extolling the importance of the knowledge of oral pathology by the Dentist in order to perform a correct differential diagnosis of other lesions to perform the appropriate treatment.
\end{abstract}

Keywords: Granuloma pyogenic; Oral patology; Oral surgery. 


\begin{abstract}
Resumen
El granuloma piógeno (PG) es una lesión benigna, no neoplásica en la cavidad oral, siendo considerada un proceso proliferativo no neoplásico (PPNN). Es una de las entidades más frecuentemente asociadas a la expansión de los tejidos blandos de la cavidad bucal, teniendo preferencia por individuos femeninos, con edades comprendidas entre los $2^{\circ}$. y el 4to. década de la vida. El tratamiento de elección es su escisión quirúrgica con un pequeño margen de seguridad, y los agentes irritantes deben eliminarse concomitantemente para la curación de la lesión. Este estudio tuvo como objetivo reportar un caso de granuloma piógeno de labio inferior asociado a trauma casual en un paciente masculino de 20 años. Los autores concluyen destacando la importancia del conocimiento de la patología bucal por parte del Cirujano Dentista para poder realizar un correcto diagnóstico diferencial de otras lesiones para poder realizar el tratamiento adecuado.

Palabras clave: Granuloma piógeno; Patología bucal; Cirugía oral.
\end{abstract}

\title{
1. Introdução
}

O Granuloma Piogênico (GP) não é considerado uma neoplasia, mas um processo proliferativo não neoplásico (PPNN) caracterizado pela expansão tecidual em regiões de tecidos moles, possuindo características específicas e requer identificação do Cirurgião-Dentista para diagnóstico e tratamento corretos (Neville et al., 2004). Também conhecido por Hemangioma Capilar Lobular (HCL) é uma lesão benigna na cavidade oral, de caráter não neoplásico. Apesar de sua denominação, não se trata de uma lesão piogênica nem granulomatosa (Neville et al., 2004; Sharma et al., 2012).

O GP é uma das entidades mais frequentemente associadas à expansão dos tecidos moles da cavidade bucal (Kruger et al., 2013). É um processo proliferativo reacional, composto por tecido de granulação com extensa vascularização, provavelmente decorrente de irritação crônica de baixa intensidade (Reyes et al., 2008; Samatha et al., 2013). Sendo definido como uma lesão do tipo reativa de ocorrência comum (Valério et al., 2011). Acomete com maior frequência indivíduos do sexo feminino, faixa etária entre a $2^{\mathrm{a}}$ e $4^{\mathrm{a}}$ décadas de vida (Reyes et al., 2008).

Hormônios sexuais femininos estão relacionados com a patogênese dessa lesão. Em gestantes, é comumente denominado granuloma gravídico ou tumor gravídico ( Borges et al., 2021; Gordón-Núñez et al., 2010; Jafarzadeh et al., 2006; Kamal et al., 2011; Kruger et al., 2013). Caracterizado por uma proliferação de tecido conjuntivo em excesso como resposta a uma agressão traumática, ocorre tanto na pele (menos usual) como na cavidade bucal (Mendonça et al., 2012).

O aspecto clínico do GP na cavidade oral é de uma lesão exofítica, séssil ou pediculada, de superfície lisa ou lobulada. A coloração pode variar do rosa ao roxo (Gordón Núñez et al., 2010; Neville et al., 2004; Sampieri et al., 2018); ou de avermelhada a acastanhada (Samatha et al., 2013). Seu tamanho pode variar de poucos milímetros a grandes lesões com vários centímetros de diâmetro. Apresenta crescimento indolor, com sangramento fácil devido à sua alta vascularização com pontos de ulceração e sangramento espontâneo (Mendes et al., 2020; Mendonça et al., 2012).

O diagnóstico diferencial deve ser feito da lesão periférica de células gigantes, fibroma ossificante periférico, hemangioma, e ainda, tumores metastáticos em sua manifestação inicial. Para um correto diagnóstico são necessários anamnese e exame clínico detalhados, bem como lançar mão de recursos complementares como exame radiográfico e biópsia (Oliveira et al., 2008; Sharma et al., 2012).

Microscopicamente, a lesão apresenta massas lobulares de elementos vasculares, semelhante ao tecido de granulação, proliferação endotelial e ainda infiltrado inflamatório misto de neutrófilos, plasmócitos e linfócitos (Oliveira et al., 2008) ${ }^{14}$.

O tratamento de eleição do granuloma piogênico consiste na excisão cirúrgica conservadora com pequena margem de segurança que é em geral curativa. Se presentes, os fatores irritativos devem ser eliminados, como doença periodontal, raízes dentárias, etc (Adeyemo et al., 2011; Binnie et al., 2000; Maciel et al., 2016; Martorelli et al., 2019; Mathur et al., 2013; Panseriya et al., 2011; Valério et al., 2011).

Embora a taxa de recorrência seja relativamente alta após remoção simples (14-16\%) (Adeyemo et al., 2011), outros métodos não convencionais para tratamento são indicados, incluindo o uso de laser de CO2, Nd: YAG ou corante pulsado, criocirurgia, injeções de etanol absoluto, tetradecil sulfato de sódio e injeções intralesionais de corticosteroides (Maciel et al., 
2016; Mathur et al., 2013; Samatha et al., 2013).

\section{Metodologia}

O presente estudo trata-se de um relato de caso sobre Granuloma Piogênico. O mesmo está relacionado a um paciente atendido em uma clínica odontológica particular na cidade do Recife-PE. Foi levantada uma hipótese diagnóstica de GP através do exame clínico durante o atendimento, e após o resultado de exame histopatológico, foi confirmada a patologia. Em relação aos aspectos éticos, após a leitura do Termo de Consentimento Livre e Esclarecido (TCLE), foi acordado e assinado pelo paciente. Além disso, pesquisas bibliográficas relacionadas ao tema GP foram realizadas em artigos científicos e livros, onde dados relevantes da literatura foram discutidos. O objetivo deste trabalho é relatar um caso de granuloma piogênico em lábio inferior relacionado a um trauma casual.

\section{Relato de Caso Clínico}

Paciente melanoderma, sexo masculino, 20 anos de idade, natural de Recife - Pernambuco, profissional autônomo, procurou a clinica privada com queixa principal de "bolha no lábio". Na história da doença atual, referiu que há cerca de 06 meses mordeu sem querer o lábio inferior e após aproximadamente um mês apareceu uma bolha no lábio que desde então veio aumentando de tamanho.

Ao exame clínico apresentava uma lesão exofítica, de inserção séssil, medindo aproximadamente $1,0 \mathrm{~cm}$ no seu maior diâmetro, de coloração de tonalidade variando do branco-amarelado ao vermelho-acastanhado (Figura 1A e B).

Figura 1 A e B. Aspecto inicial da lesão.
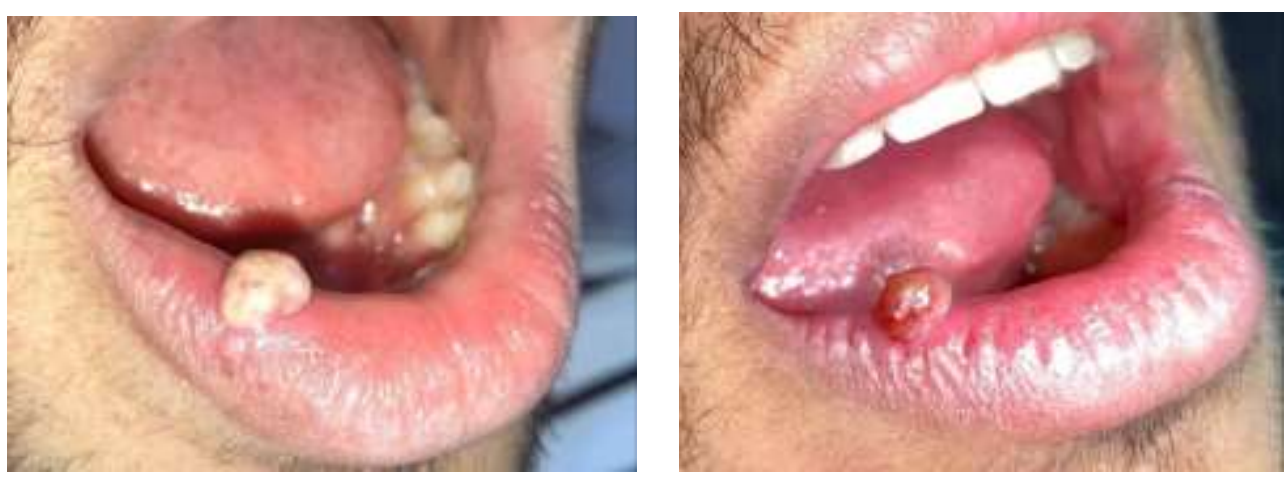

Fonte: Autores (2021).

Confrontando os dados anamnéticos com o aspecto clínico da lesão, elencamos granuloma piogênico como nossa hipótese diagnóstica e propusemos a exérese da lesão mediante biópsia incisional sob anestesia local.

Após leitura, concordância e assinatura do Termo de Consentimento Livre e Esclarecido (TCLE), os exames préoperatórios foram solicitados e, por encontrarem-se dentro do padrão de normalidade, a cirurgia foi programada.

A antissepsia intra e extra oral foi empreendida mediante uso de solução de digluconato de clorexidina a $0,12 \%$ e a $2 \%$ respectivamente, e logo após aposto o campo operatório.

Foi realizada a anestesia local por bloqueio nervo mentoniano com solução de cloridrato de mepivacaína a $2 \%$ com epinefrina 1:100.000, que com fins de hemostasia periférica foi complementada com infiltração no entorno da lesão (Figura 2A e B). 
Figura 2A e B. Bloqueio do nervo mentoniano e infiltração local.

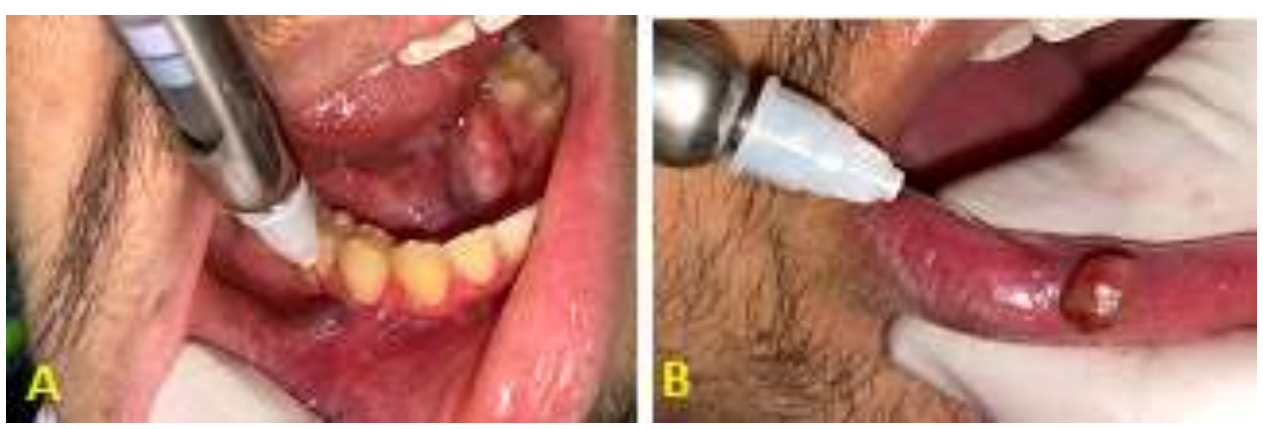

Fonte: Autores (2021).

Com o uso do bisturi de Bardpaker No. 3 municiado com lâmina 15-C, a incisão foi empreendida verticalmente de forma elíptica sobre o vermelhão do lábio respeitando-se as pregas labiais naturais e conformando uma margem de segurança de aproximadamente $2 \mathrm{~mm}$. (Figura 3 ).

Figura 3. Incisão com margem de segurança de aproximadamente $2 \mathrm{~mm}$.

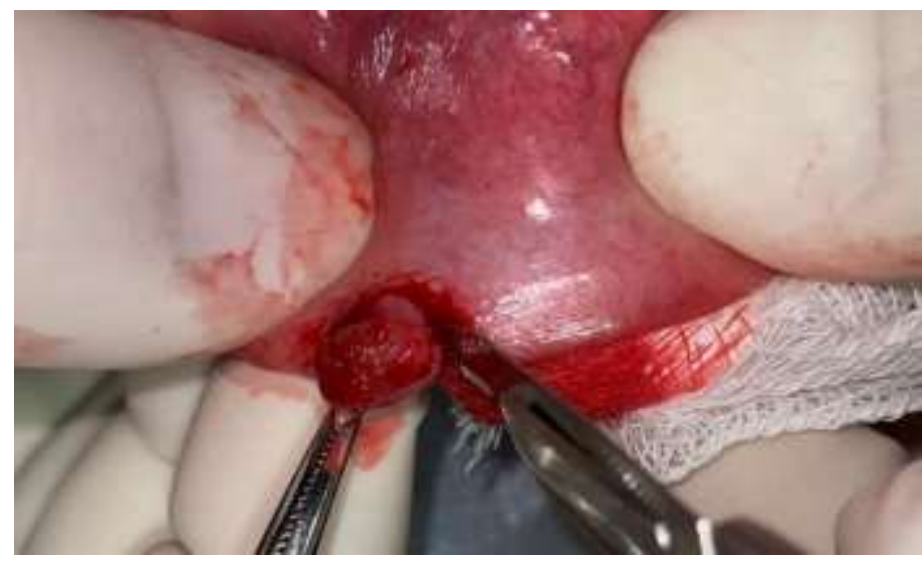

Fonte: Autores (2021).

Após a exérese da lesão, a peça operatória foi fixada imediatamente em solução de formol a 10\% (Figura 4).

Figura 4. Aspecto macroscópico da peça operatória.

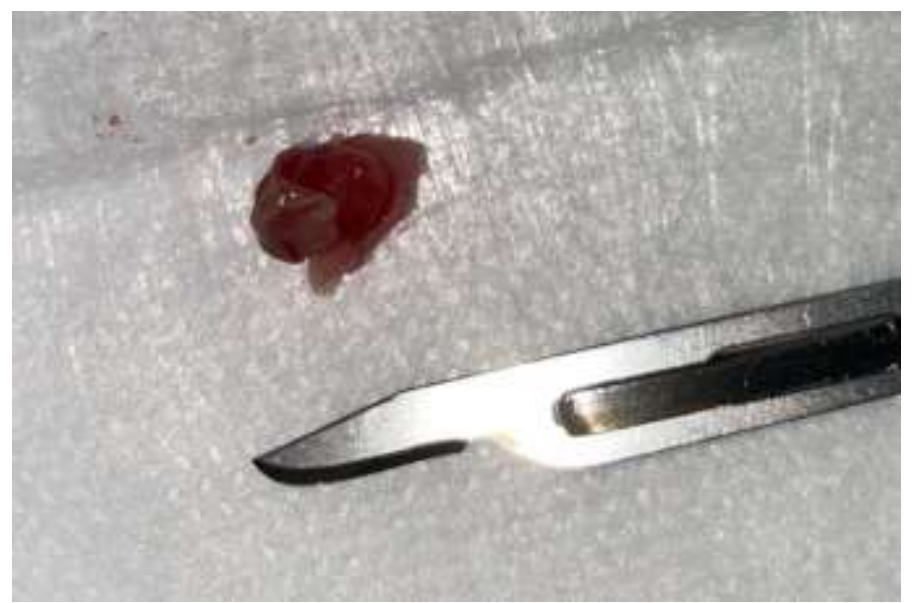

Fonte: Autores (2021). 
Os procedimentos de hemostasia foram feitos, a seguir, inclusive às expensas do bisturi eletrônico em modo coagulação (Figura 5).

Figura 5. Hemostasia através da eletrocoagulação.

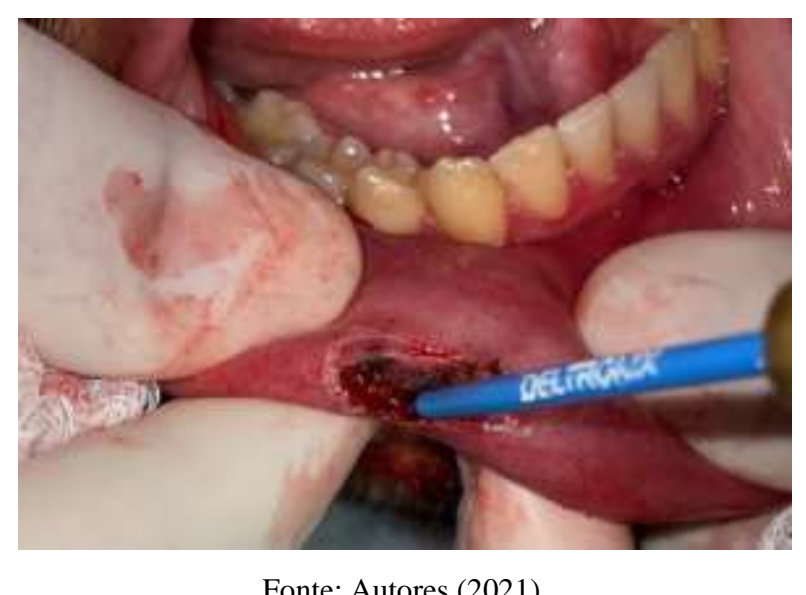

A seguir, a ferida foi suturada, em pontos isolados, com fio de nylon monofilamentar 6-0. As recomendações pósoperatórias foram fornecidas por escrito e prescrito dipirona sódica 500mg, 01 comprimido até de 06/06hs, apenas em caso de dor.

A sutura foi removida no $7^{\circ}$ dia do pós-operatório, que transcorreu sem qualquer intercorrência.

O resultado do exame histopatológico (Figura 6) foi compatível com granuloma piogênico, confirmando, em definitivo, a nossa hipótese diagnóstica.

Figura 6. Fotomicrografia da peça operatória.

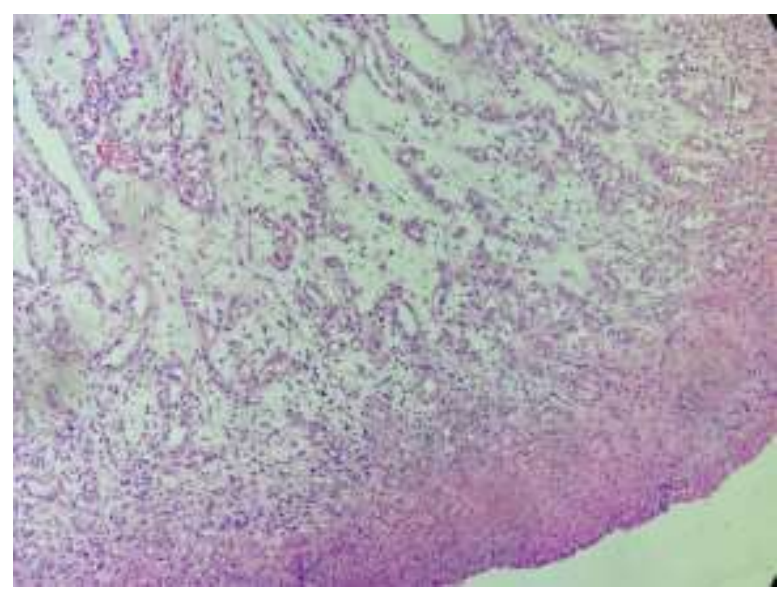

Fonte: Autores (2021).

O aspecto pós-operatório de 30 dias pode ser observado nas Figura 7A e B. 
Figura 7 A e B. Aspecto pós-operatório com 30 dias.
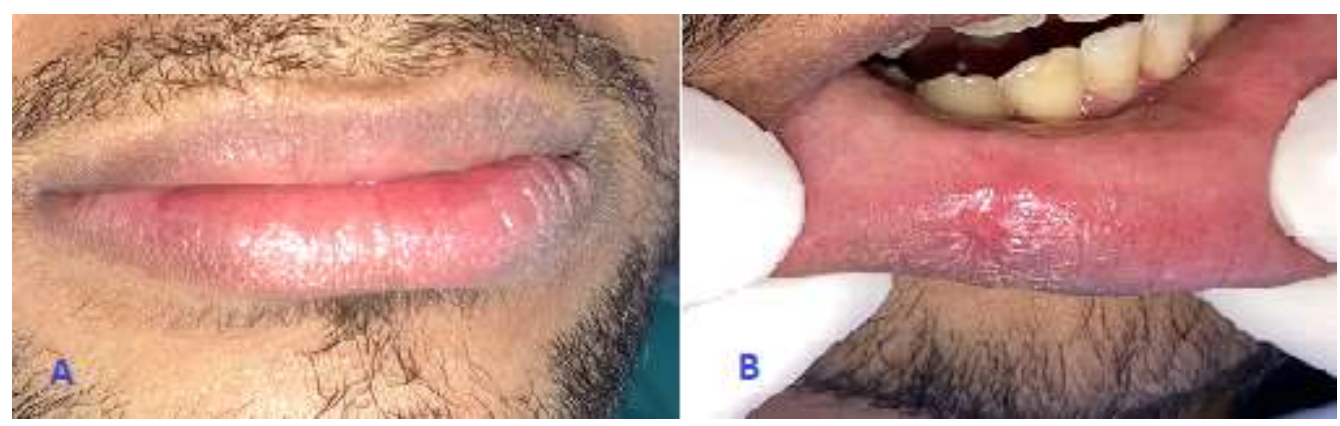

Fonte: Autores (2021).

\section{Resultados e Discussão}

O GP é uma lesão de ocorrência comum na cavidade bucal, acometendo com maior frenquencia a $2^{\mathrm{a}}$. e $3^{\mathrm{a}}$. década de vida, com predileção pelo sexo feminino, o que corrobora com o caso relatado (Samatha et al., 2013). Muito embora possa estar relacionado com alterações hormonais ou gestação, especificamente neste caso não havia qualquer enquadramento nestes parâmetros (Jafarzadeh et al., 2006; Kamal et al., 2011; Samatha et al., 2013). Por ser uma lesão que está associada frequentemente a trauma frequente ou presença de agentes irritantes, neste caso não houve necessidade por ter sido apenas um único traumatismo referido pelo paciente.

Desta forma foi tão somente realizada a exérese da lesão com pequena margem de segurança, o que culminou com a cura da patologia e permitiu realizar o diagnóstico definitivo e diferencial de outras lesões da cavidade bucal. Não ocorreu reincidência da lesão, muito embora seja possível ocorrer já que a literatura informa uma taxa residual de 14-16\% (Adeyemo et al., 2011).

\section{Considerações Finais}

O GP é lesão não-neoplásica de ocorrência comum na cavidade bucal. É, portanto, necessário conhecimento da Patologia Bucal por parte do Cirurgião-Dentista no sentido de realizar o diagnóstico diferencial de outras lesões e, através do tratamento correto, contribuir para a manutenção da saúde bucal do paciente.

\section{Referências}

Adeyemo, W. L., Hassan, O. O, \& Ajayi, O. F. (2011). Pregnan- cy-associated pyogenic granuloma of the lip: a case report. Niger J Med. 20(1):179-80 Binnie, W. H,. (2000). Periodontal cysts and epulides. Periodontol. 21(10):16-32.

Borges, E. F. D. et al. (2021). Granuloma piogênico em assoalho bucal: relato de caso. Rev. cir. traumatol. Buco-Maxilo-Fac. 21(1), 32-35

Gordón-Núñez M. A., Carvalho, M. V., Benevenuto, T. G., Lopes, M. F. F., Silva, L. M. M. \& Galvão, H. C. (2010). Oral Pyogenic Granuloma: A Retrospective Analysis of 293 Cases in a Brazilian Population. Oral Maxillofac Surg. 68(9): 2185-8.

Jafarzadeh H, Sanatkhani M, Mohtasham N. Oral pyogenic granuloma: a review. J Oral Sci. 2006 Dec;48(4):167-75.

Kamal R, Dahiya P, Palaskar S, Shetty VP. Comparative analysis of mast cell count in normal oral mucosa and oral pyogenic granuloma.J ClinExp Dent. 2011;3(1):e1-4.

Kruger, M. S. M. et al. (2013). Granuloma gravídico - relato de caso. Odontol. Clín.-Cient. (Online) [online]. 12(4): 293-5. http://revodonto.bvsalud.org/scielo.php?script=sci_arttext\&pid=S1677-38882013000400011\&lng=pt\&nrm=iso. ISSN 1677-3888.

Maciel, J. A. C., Oliveira, V. B. V., J.L.A. \& Silva, I. I. C et al. (2016). Granuloma Piogênico Labial em Gestante com Aparelho Ortodôntico: Etiologia Sinergística em Local Atípico. Braz. J. Surg. Clin. Res. V.14,n.1,pp.16-20.

Martorelli, S. B. F., Martorelli, F. O., Lins, G. P. F., Andrade, F. B. M., Lacerda, E. P. M. \& Vasconcellos, C. G. P. P. (2019). Granuloma Piogênico de Ápice Lingual: Relato de Caso. Odontologia clínico-científica (impresso), 18, 315-318. 
Research, Society and Development, v. 10, n. 16, e21101623099, 2021

(CC BY 4.0) | ISSN 2525-3409 | DOI: http://dx.doi.org/10.33448/rsd-v10i16.23099

Mathur, H., Shetti, A. \& Charantimath, S. (2013). A Common Oral Lesion in an Unusual Site -Pyogenic Granuloma Of Lip. Int J Sci Res. 2(3):302-3

Mendes, T. C. et al (2020) Granuloma Piogênico incomum no lábio superior: Relato de Caso.Brazilian Journal of Implantology and Health Sciences. 2 35-44.

Mendonça, J. C. G., Gaetti-Jardim E. C., Macena, J. A., Teixeira, F. R., Santos, C. M., Oliveira, M. M., Masocatto, D. C. \& Quadros, D. C. (2015). Granuloma piogênico de grandes proporções: relato de caso clínico-cirúrgico. Arch Health Invest. 4(3): 47-51

Neville, B. W., Damm, D. D., Allen C. M.,Bouquot, J. E. (2004). Patologia oral e maxilofacial. (2a ed.) Guanabara Koogan.

Oliveira, T. M., Greghi, S. L., Taveira, L. A., Santos, C. F., Machado, M. A. \& Silva, S. M. (2008). Surgical Removal of an Oral Pyogenic Granuloma and Subsequent Root Coverage With a Pedicle Graft. J Dent Child (Chic). 75(1):55-8.

Panseriya, B. J. \& Hungund, S. (2011). Pyogenic Granuloma associated with periodontal abscess and bone loss. A rare case report. Contemp Clin Dent. 2(3):2404.

Reyes, A. et al. (2008). Granuloma Piogênico - enfoque na doença periodontal como fator etiológico-Rev Clín Pesq Odontol; 4(1): 29-33.

Samatha, Y. et al. (2013) . Management of Oral Pyogenic Granuloma With Sodium Tetra Decyl Sulphate. A Case Series. NY State Dent. 79(4):55-7.

Sampieri, M. B. S. et al (2018). Exuberante granuloma piogênico em localização incomum: Relato de caso. Rev. cir. traumatol. Buco-Maxilo-Fac. 18(3), 22-25

Sharma, A., Vikram, A., Bhadani, P. P, Singh, G, \& Kumar, A. (2012). Aggressive invasive oral pyogenic granuloma: A case report. Indian J Dent. 3(2): 81-5.

Valério, R. M., Moreschi, E., Shultz, C. Y. K., \& Kamei, N. C. (2011). Granuloma Piogênico: relato de caso clínico-cirúrgico. Revista Dens, 19(2) 